\title{
Differential second-order aversive conditioning using contextual stimuli
}

\author{
FRED J. HELMSTETTER and MICHAEL S. FANSELOW \\ Dartmouth College, Hanover, New Hampshire
}

\begin{abstract}
Two experiments were conducted to determine if contextual stimuli used as $\mathbf{S}_{\mathbf{2}}$ in a higher-order differential conditioning procedure would control the performance of rats. Discrete stimuli were first paired with footshock in a separate training context. During second-order training, a shockassociated discrete stimulus was presented in one of two discriminable observation chambers. Over 4 days of training, subjects engaged in more freezing in the context associated with an excitatory discrete $S_{1}$ relative to a context in which no discrete stimulus, or a stimulus that had been explicitly unpaired with shock delivery, was presented. After acquisition of the second-order discrimination, animals were returned to the original training context where they received a "signaled inflation" treatment designed to change the current value of $S_{1}$ and the US. This postconditioning manipulation did not selectively affect performance of defensive freezing or conditional analgesia in $\mathrm{S}_{2}$.
\end{abstract}

Higher-order conditioning refers to the process through which stimuli that have gained the ability to control responding through a direct relationship with a biologically significant event can, when subsequently paired with a "neutral" stimulus, support further conditioning. While this phenomenon was first demonstrated in Pavlov's $(1927 / 1960)$ laboratory early in this century, higher-order conditioning has received rigorous empirical and theoretical treatment only in the relatively recent past (Rescorla, 1980). Aside from the obvious utility of this concept in the associationist's theoretical account of many types of complex behavior, higher-order learning may in addition be viewed as a useful tool in the detailed laboratory analysis of traditional topics in associative learning (Rescorla, 1973,1980 ). Higher-order conditioning procedures have aided in the investigation of such topics as the nature of stimulus representations (Holland \& Straub, 1979; Rescorla, 1979), the role of the CS in determining the form of the conditional response (Holland, 1977), the nature of associations in autoshaping (Rashotte, 1981), within compound associations, and the facilitory effects of stimulus similarity and spatial contiguity in Pavlovian conditioning (Rescorla, 1980).

Rescorla (1973) has pointed out that an animal's response to higher-order conditional stimuli may reflect the existence of a number of possible associations. For example, since a relationship has been programmed between $S_{2}$ and $S_{1}$, an association may be formed between these two stimuli. Presentation of $S_{2}$ might thus activate

This research was supported by National Science Foundation Grant 86-06787 awarded to Michael S. Fanselow, who is now at the Department of Psychology, University of California at Los Angeles, Los Angeles, CA 90024-1563. Correspondence should be addressed to Fred J. Helmstetter, Department of Psychology, Dartmouth College, Hanover, NH 03755. some memory of $S_{1}$, which by virtue of its association with the unconditioned stimulus causes a CR. Thus, second-order responding may be "mediated" by the firstorder stimulus. A second possibility would be that $S_{2}$ directly activates a representation of the US. This is possible, because if we assume that $S_{1}$ is able to evoke a representation of the US, then, during second-order conditioning, $S_{2}$ may be paired with that representation. According to this view, presentation of $S_{2}$ will retrieve a memory of the US, which should cause the animal to respond. The third major possibility is that $S_{2}$ becomes directly associated with a response evoked by $S_{1}$.

One approach commonly used to study the elements of associative learning rests on the assumption that animals possess memories of individual stimulus events that are modifiable (Rozeboom, 1958). In first-order conditioning, for example, nonassociative "devaluation" or "inflation" of an animal's memory of the US will influence the strength of the CR in the presence of a signal for that US (Holland \& Straub, 1979; Rescorla, 1974). In secondorder conditioning, manipulations of this type may or may not be effective. Several reports indicate that responding to $S_{2}$ is often independent of the current value of either $S_{1}$ (Amiro \& Bitterman, 1980; Archer \& Sjoden, 1982; Holland \& Rescorla, 1975; Rizely \& Rescorla, 1972) or the US (Davey \& McKenna, 1983; Rescorla, 1974). However, with other procedures, responses to higher-order stimuli are dependent on current values of $S_{1}$ or the US (Rashotte, Griffen \& Sisk, 1977; Rescorla, 1979; Ross, 1988). Although a number of different species and conditioning preparations have been used in these studies, the two procedural variables that seem to be most important in determining the sensitivity of second-order CRs to manipulation of components of the $S_{1}$-US association are the nature of the conditional stimuli used and the temporal relationship of their presentation. 
In a second-order autoshaping preparation in which stimuli are presented sequentially to pigeons, if $S_{2}$ and $S_{1}$ share the same modality, the response to $S_{2}$ seems to depend on a stimulus-stimulus $\left(\mathbf{S}_{2}-S_{1}\right)$ association. Nairne and Rescorla (1981) reported that $S_{2}$ was sensitive to $S_{1}$ extinction only when both stimuli were visual. If an auditory $S_{1}$ was used to reinforce a visual $S_{2}$, higher-order responding continued after $S_{1}$ extinction (but see Rashotte et al., 1977, Experiment 2). A similar result was reported after sequential presentation of similar versus dissimilar stimuli to rats in a conditioned suppression preparation. Responding to $S_{2}$ was reduced after extinction of $S_{1}$ only if the two stimuli were tones of different frequencies (Rescorla, 1980). Yet in taste-aversion conditioning with rats, for example, employing stimuli of the same modality (olfactory) will produce S-S learning only if they are presented simultaneously. Sequential presentation of the same stimuli produced higher-order responding that is insensitive to $S_{1}$ manipulation (Robertson, Krane, \& Garrud, 1984). This effect of temporal relation also holds for conditioned suppression in rats when stimuli of different modalities are used. Rescorla (1982) found that simultaneous presentation of stimuli of different modalities tended to produce $S-S$ learning, whereas sequential presentation of the same stimuli resulted in comparable levels of second-order responding that was insensitive to extinction of $S_{1}$.

In recent years, increasing attention has been paid to the role of contextual stimuli in traditional conditioning situations (Balsam \& Tomie, 1985). It is by now well established that a context is in many ways similar to a discrete unimodal CS when used in first-order conditioning (e.g., see Odling-Smee, 1978), although it may possess some unique properties (Bouton \& Bolles, 1985; Miller \& Schachtman, 1985). The role of contexts in higherorder conditioning has received less attention, however. Marlin (1983) demonstrated that second-order conditioning of a tone $S_{2}$ could be established if the tone was presented to rats in a context made excitatory with footshock. More recently, Rescorla (1984) used contextual stimuli in a differential second-order conditioning design. The general activity of pigeons tended to increase in a context in which a food-associated keylight was presented, relative to another context in which a signal that had been explicitly unpaired with food was inserted. The present experiments were designed to determine whether contextual stimuli can function as $S_{2}$ in aversive Pavlovian conditioning with rats.

\section{EXPERIMENT 1}

The design of Experiment 1 was similar to that reported by Rescorla (1984). During first-order conditioning, two discrete stimuli were presented in a distinctive training context. One of these $\left(S_{1}+\right)$ was always followed by footshock, whereas the other $\left(S_{1}-\right)$ was never followed by shock. During second-order conditioning, $S_{1}+$ was presented in one context $\left(S_{2}+\right)$, and $S_{1}-$ was presented an equal number of times in another context $\left(S_{2}-\right)$. As an index of conditioning, the amount of time each subject spent freezing during presentation of each stimulus was recorded (Bouton \& Bolles, 1980; Sigmundi \& Bolles, 1983).

Since the nature of associations in second-order conditioning is at least partially determined by the properties of the conditional stimuli involved, the relation between second-order associations involving contexts and those with discrete stimuli is of interest. To determine if higherorder responding to the context was dependent on an S-S association, we employed a "signaled inflation" procedure, which was intended to modify the value of both components of the $S_{1}$-US association. If this manipulation affects the response to $S_{2}$, then this response is likely mediated by either $S_{1}$ or some representation of the US. Note that when Ross (1988) demonstrated second-order conditional analgesia, US devaluation was effective even though his conditioning parameters might be expected to produce S-R learning (sequential presentation of dissimilar stimuli). In the present experiment, we measured analgesia and freezing simultaneously after signaled inflation, in order to determine the extent to which the two CRs would covary.

\section{Method}

Subjects. Sixteen female Long-Evans rats bred in the Dartmouth psychology animal colony served as subjects. The animals were housed in groups up to the first day of handling, after which they were maintained individually in hanging stainless steel cages with ad-lib access to lab chow (Agway) and tap water. The subjects were between 90 and 120 days old at the time of testing. Each rat was handled for 2 min a day for 5 days prior to training. A 14:10 h light:dark cycle remained in effect throughout the experiment. All manipulations began approximately $4 \mathrm{~h}$ before the onset of the dark portion of the cycle.

Apparatus. Conditioning took place in three sets of observation chambers. Each chamber was illuminated by a 7.5-W red light bulb and enclosed within a sound-attenuating chest. The first set of chambers (Context X), constructed entirely of clear Plexiglas, measured $24 \times 21.6 \times 39 \mathrm{~cm}$ deep. The two sidewalls were painted gray. The floor of each was composed of 18 brass rods $(0.35 \mathrm{~cm}$ in diameter, spaced $1.4 \mathrm{~cm}$ apart, center to center). The grid floor of each chamber was connected to its own Grason-Stadler shock generator so that scrambled AC footshock could be delivered. This first set of chambers was always cleaned with a $10 \%$ acetic acid solution. A 15 -W white light mounted in the chest above the observation chamber and a $2500-\mathrm{Hz}$ tone ( $72 \mathrm{~dB}$, A scale) served as discrete stimuli during first-order conditioning. All manipulations involving footshock occurred in Context $X$.

Two additional sets of observation chambers located in an adjacent room served as contextual stimuli during second-order conditioning. These chambers were made of stainless steel and Plexiglas; they measured $23.5 \times 29 \times 19.5 \mathrm{~cm}$. In one set (Context A), a masonite insert completely covered the grid floor. Context A was always cleaned with a $5 \%$ ammonium hydroxide solution. In the second set (Context B), a $20.5 \times 28 \mathrm{~cm}$ piece of hardware cloth was placed over the grid floor, and a masonite insert was placed in the chamber so that it extended diagonally from the upper right corner 
to a point $9 \mathrm{~cm}$ from the front wall, thus covering this wall and part of the floor. Context $B$ was cleaned with a $1 \%$ solution of imitation peppermint (Durkee) and tap water. All of the chambers were prepared so that the $15-\mathrm{W}$ white light and $2500-\mathrm{Hz}$ tone could be presented in a manner essentially identical to that used in Context X.

Procedure. Prior to first-order conditioning, all the animals were preexposed to Context $X$ for $20 \mathrm{~min}$ and then returned to the colony room. The subjects were randomly assigned to two groups, and on each of the following 5 days they received one 11.5 -min session of differential first-order conditioning. The rats in Group $L+/ T-$ received four presentations of the light $\left(S_{1}+\right)$ followed by a $1 \mathrm{~mA} / .75 \mathrm{sec}$ footshock and four nonreinforced presentations of the tone $\left(S_{1}-\right)$ each day. Group $\mathrm{T}+/ \mathrm{L}-$ received identical treatment, except that shock followed the tone rather than the light. All firstorder CSs were $20 \mathrm{sec}$ long. The stimuli were programmed to occur pseudorandomly, and order of presentation within and between groups was counterbalanced each session. The minimum intertrial interval was $20 \mathrm{sec}$. During the first presentation of each stimulus in each session, the amount of time spent freezing during the signal was determined with a time-sampling procedure that permitted groups of four rats to be observed simultaneously in a given session. Each rat's behavior was scored as active or freezing a total of three times at 6-sec intervals during presentation of the stimulus. Freezing was defined as the lack of all visible movement apart from that required by respiration. After 5 days of first-order conditioning, each subject was given two 20-min exposures (one per day) to Context $X$, during which no shocks or discrete stimuli were presented.

Prior to second-order conditioning, the subjects from each group $(\mathrm{L}+/ \mathrm{T}-$ and $\mathrm{T}+/ \mathrm{L}-)$ were assigned an $\mathrm{S}_{2}+$ and an $\mathrm{S}_{2}$ - context such that the modality of first-order stimuli and their relation to Contexts $A$ and $B$ were completely counterbalanced. Second-order training was conducted as follows: Once each day, the rats were exposed to both contexts for $4 \mathrm{~min} 40 \mathrm{sec}$ each. In the context designated $S_{2}+$, the discrete stimulus that had been paired with shock during first-order conditioning was presented for $20 \mathrm{sec}$, starting $4 \mathrm{~min}$ after placement in the chamber. The animal remained in the chamber for an additional $20 \mathrm{sec}$ after stimulus termination. In $\mathrm{S}_{2}-$, animals were treated identically, except that the stimulus that was unpaired with shock in first-order training was presented. The percentage of time spent freezing was recorded during the 4-min period prior to discrete stimulus presentation in each context. Freezing was also recorded during presentation of the tone or the light. Four days of second-order training were completed.

Postconditioning manipulations were preceded by a single 20min exposure to the first-order training context $(\mathrm{X})$, during which no CSs or shocks were presented. On the following day, groups were formed such that one half of the animals from each of the first-order stimulus modality groups $(\mathrm{L}+/ \mathrm{T}-$ and $\mathrm{T}-/ \mathrm{L}+$ ) now received a series of four presentations of $S_{1}+$ each, followed by a single $3 \mathrm{~mA} / .75 \mathrm{sec}$ footshock in Context $X$ (the inflation group). The remaining animals were given an equal number of nonreinforced presentations of $S_{1}+$ (the extinction group). Presentation of stimuli was programmed to occur pseudorandomly over the course of the 20 -min session. On the 2 days after this treatment, all the subjects were given 20 -min exposures to Context $\mathrm{X}$, during which no stimuli were programmed.

On the following day, a final test session was conducted that consisted of recording the animals' behavior during exposure to $S_{2}+$ and $S_{2}-$. In addition to the freezing measure, second-order conditional analgesia was measured with the formalin test (Dubuisson \& Dennis, 1977). Each rat was given a subcutaneous injection of $15 \%$ formalin in saline under the dorsal surface of the right hind paw and returned to the home cage. After $25 \mathrm{~min}$, the subjects were placed in either $S_{2}+$ or $S_{2}-$ (order counterbalanced) and scored for both freezing and the amount of stereotyped licking and lifting behavior associated with the injured paw for a 4-min period.

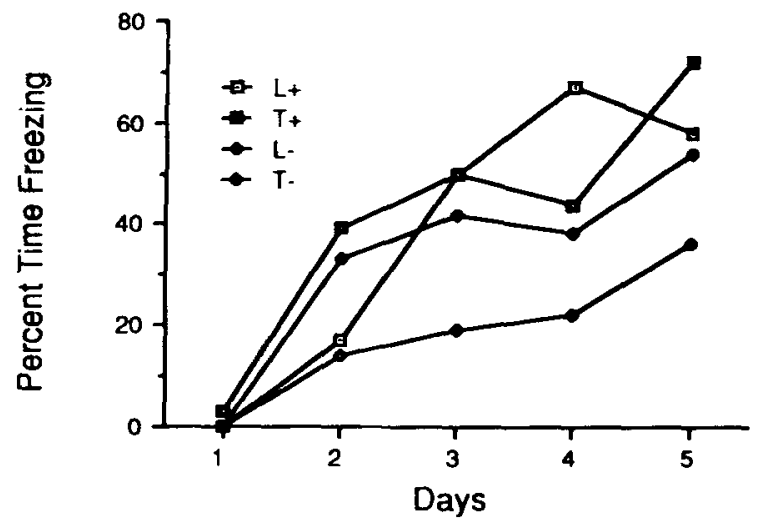

Figure 1. Mean percent freezing scores recorded during the first presentation of each 20-sec stimulus on each day of first-order training. The data are from two independent groups $(L+/ T-$ and $T+/ \mathbf{L}-)$, which received an equal number of presentations of each stimulus. For group $\mathbf{L}+/ \mathbf{T}-$ the light was always followed by a single $1 \mathrm{~mA}$ shock, whereas shock followed the tone for group $\mathrm{T}+/ \mathrm{L}-$.

\section{Results}

Multivariate repeated-measures analysis of variance (MANOVA) conducted on freezing responses to $S_{1}+$ and $S_{1}-$ on the first presentation each day during first-order training revealed a reliable modality $\times$ contingency $\times$ trial interaction $[F(4,11)=9.40, p<.01]$. Inspection of Figure 1 indicates that while the tone and the light tended to provoke different amounts of freezing, the animals did acquire the discrimination reliably over the 5 days of training.

The acquisition of second-order responding is depicted in Figure 2. A repeated-measures MANOVA on the freezing scores recorded in $S_{2}+$ and $S_{2}$ - prior to presentation of discrete stimuli indicated that the animals acquired the second-order discrimination reliably as indexed by the context $\left(S_{2}+\right.$ vs. $\left.S_{2}-\right) \times$ trial interaction $[F(3,12)$ $=4.49, p<.03]$. Modality of first-order stimuli had no

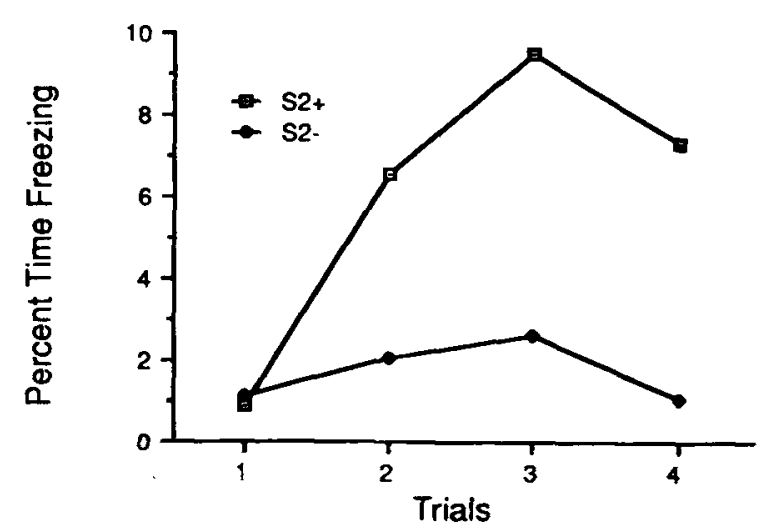

Figure 2. The percent of time each animal spent freezing in the presence of contextual second-order stimuli. $S_{2}+$ refers to the context in which the first-order signal that had been paired with shock was presented. The explicitly unpaired discrete stimulus was presented in $\mathbf{S}_{\mathbf{2}}-$. 
effect on the amount or rate of acquisition of second-order conditioning. However, as can be seen in the data recorded during the 20-sec presentation of $S_{1}$ in each context on each day (depicted in Figure 3), stimulus modality still affected the amount of first-order responding. This was supported by a significant modality $\times$ contingency interaction $[F(1,14)=11.35, p<.01]$. The trend toward extinction of the first-order excitor over the course of second-order training was statistically marginal $[F(3,12)$ $=2.92, p=.07]$.

The upper panel of Figure 4 depicts the amount of time the animals spent freezing when returned to $S_{2}+$ and $S_{2}-$ after postconditioning manipulations intended to modify the $S_{1}$-US relationship. Signaled inflation had no selective effect on the response to $S_{2}$ as indicated by the group $\times$ context interaction $[F(1,14)<1]$. There was no reliable main effect for inflation on second-order responding $[F(1,14)=1.81, p>.05]$, and this treatment did not disrupt performance of the discrimination $[F(1,14)=$ $23.88, p<.01]$.

The lower portion of Figure 4 represents formalininduced behavior observed simultaneously with freezing during the test session. Since analgesia is reflected in a suppression of formalin-induced behavior, lower numbers indicate more analgesia. Scores in the formalin test generally obey a Poisson distribution. Therefore, statistical analyses were conducted on the square root of the percent time each animal spent engaged in formalin-related behavior to conform to the assumptions of MANOVA. The pattern of results for hypoalgesia was essentially the same as for freezing. Animals placed in $S_{2}+$ were less likely to engage in formalin-induced behavior than they were in $S_{2}-$. This observation was supported by a significant main effect for context $[F(1,14)=7.49, p<.02]$. Signaled inflation had no effect on second-order analgesia $[F(1,14)=1.83, p>.05]$. This manipulation had no selective effect on recuperative behavior in $S_{2}+$, which

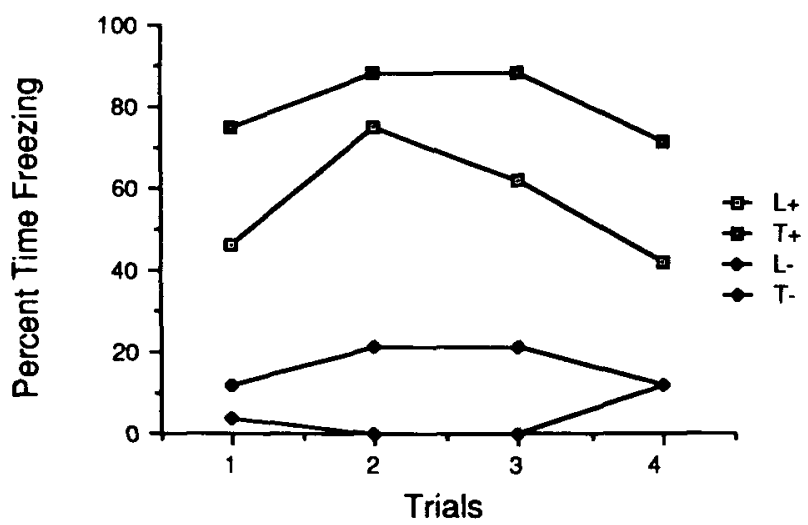

Figure 3. The response to each of the first-order stimuli during the course of second-order conditioning. Data were recorded during the 20-sec presentation of $S_{1}$ in each of the contexts used as $S_{2}+$ and $S_{2}-$.
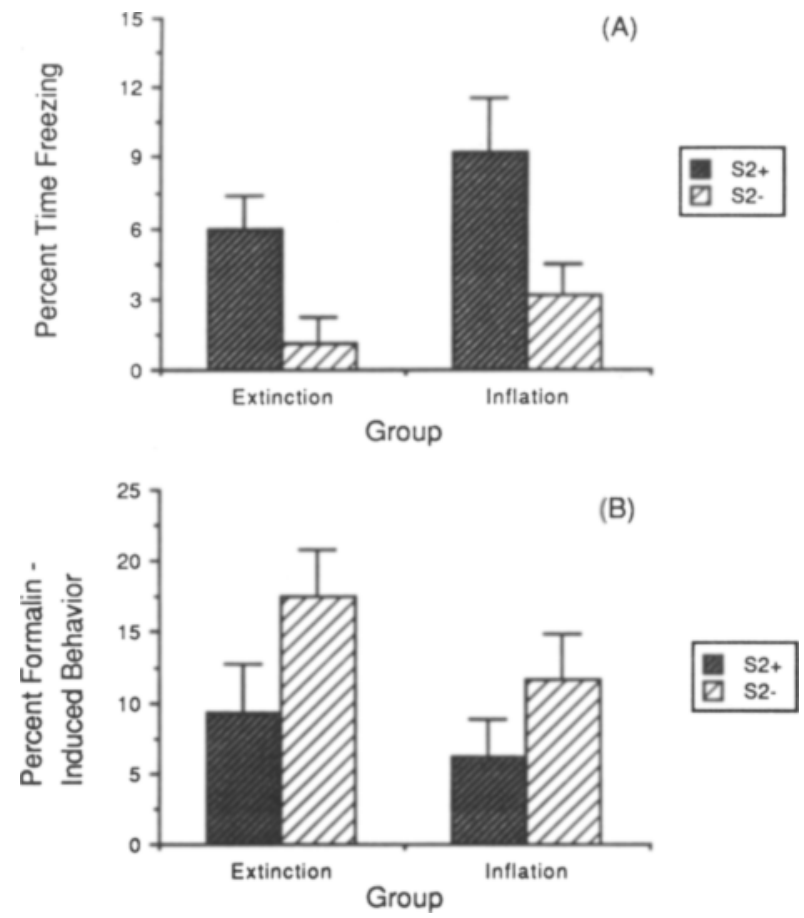

Figure 4. The effects of postconditioning manipulation with the signaled inflation procedure on freezing and conditioned analgesia. Data shown in $A$ represent the mean percent of time spent freezing during a 4-min period in both $S_{2}+$ and $S_{2}-$. The lower panel (B) depicts the amount of stereotyped behavior the animals displayed in response to a subcutaneous formalin injection. The suppression of formalin behavior indicates hypoalgesia.

was reflected in the lack of a group $\times$ context interaction $[F(1,14)<1]$.

\section{EXPERIMENT 2}

The results of Experiment 1 indicate that rats are able to learn higher-order context discriminations on the basis of footshock. While the lack of effect of our postacquisition inflation treatment is in some sense consistent with other studies of this type, these results must be interpreted with caution, since no independent measurement of the response to $S_{1}+$ was made after this phase. Thus, our null result might have been caused by an ineffective inflation or extinction procedure, although very similar parameters have been shown to be effective (Rescorla, 1974). Experiment 2 incorporated a number of procedural changes to address this. The shock intensities in inflation now differed by a factor of 6 rather than the 3-fold increase used in Experiment 1 . In addition to the inflation and extinction groups, a third group was included; it received signaled presentations of shocks with the same intensity that was used during original $S_{1}$ training. This "reminder" treatment was intended to reinstate any of $S_{1}$ 's associative strength that might be lost during non- 
reinforced pairings with $S_{2}$. Also, the trials in this third phase were distributed over 2 days, rather than all being given on a single day.

\section{Method}

Subjects. Eighteen Long-Evans female rats of ages ranging from 100 to 120 days at the time of testing were used as subjects. The animals were maintained and adapted to the experimental procedures as in Experiment 1.

Apparatus. The observation chambers previously described were used again. They were prepared to form three discriminable contexts $(\mathrm{X}, \mathrm{A}$, and $\mathrm{B})$, as in the last experiment. The same $72-\mathrm{dB}$ $2500-\mathrm{Hz}$ tone was also used.

Procedure. Following adaptation to handling and transportation, all the subjects were given one 20 -min exposure to Context $X$. On the next day, first-order training began. This consisted of four $40-$ sec presentations of the tone, each one followed immediately by a single $.5 \mathrm{~mA} / .5 \mathrm{sec}$ footshock on each of 5 consecutive days as in the last experiment. Each session was 11.5-min long; the stimuli were programmed to occur pseudorandomly. The minimum ITI was $20 \mathrm{sec}$. The amount of freezing during the tone was recorded. The light was never presented. Two days of exposure to Context $X$, consisting of one 20 -min period each day, followed first-order conditioning.

Second-order conditioning was conducted as in Experiment 1. Once each day, every subject was placed in both Context $A$ and Context B, with order counterbalanced, for a single 5-min period. After 4 min had elapsed, the animals in $S_{2}+$ received a single 40 sec presentation of the tone. The animals in $S_{2}-$ received no discrete stimuli. The amount of freezing during the $4 \mathrm{~min}$ prior to the tone in $S_{2}+$, and the corresponding 4 -min period in $S_{2}-$, were recorded. Four days of second-order training were completed.

On the next day, the animals were returned to Context $X$ for postacquisition training. The subjects were randomly assigned to three independent groups $(N=6)$. The extinction group received $40-\mathrm{sec}$ presentations of the tone without shock. The animals in the inflation group received the tone followed by a $3 \mathrm{~mA} / .5 \mathrm{sec}$ footshock. The third group received a reminder treatment consisting of $S_{1}$-US pairings using a $.5 \mathrm{~mA} / .5$ sec shock, just as in first-order conditioning. All the subjects were given two trials a day, which were programmed to occur randomly during 11.5-min sessions on 2 consecutive days.

Prior to testing in $S_{2}$, all the subjects were given a single 20-min exposure to Context $\mathrm{X}$. On the next day, the animals were placed in $S_{2}+$ and $S_{2}-$, and the amount of freezing was recorded for $4 \mathrm{~min}$. After $4 \mathrm{~min}$ had elapsed, the tone was presented for $40 \mathrm{sec}$. The percentage of time spent freezing during this period was also recorded. On the following day, all the subjects were returned to Context $X$, and after $4 \mathrm{~min}$ they were given a single presentation of the tone.

\section{Results}

Acquisition of freezing in response to the tone proceeded normally. The animals reached asymptote after approximately four trials, at which point they were freezing during $65 \%$ of the stimulus period, on the average. A repeated-measures MANOVA indicated that the acquisition was reliable $[F(4,68)=46.71, p<.01]$. Higher-order conditioning was again supported by the tone. As can be seen in Figure 5, the animals spent more time freezing in the context in which the tone was presented than they did in $S_{2}$ - over the course of four trials. This was supported by a significant context $\times$ trial interaction $[F(3,15)=7.66, p<.01]$.

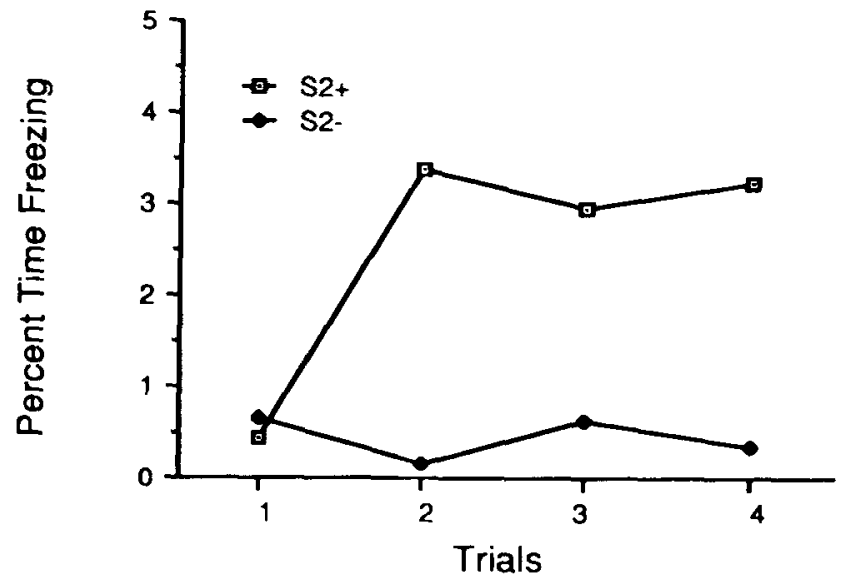

Figure 5. The acquisition of second-order context conditioning in Experiment 2. In $S_{2}+$, a tone that had previously signaled $.5 \mathrm{~mA}$ footshocks was presented once each day. No discrete stimuli were presented in $S_{2}-$.

Figure 6 represents performance in each second-order context on the test day following signaled inflation training. As in Experiment 1, postacquisition manipulation of the $S_{1}$-US association had no detectable effect on responding to $S_{2}$, as indicated by the main effect for group $[F(2,15)<1]$. The animals continued, however, to discriminate reliably between the two contexts $[F(1,15)=$ $7.84, p<.02]$. Importantly, the group $\times$ context interaction was not significant $[F(1,15)<1]$. Signaled inflation training did modify the response to the tone $S_{1}$. This is shown in Figure 7, which depicts the amount of freezing observed during a single presentation of $S_{1}$ in either the first-order training context or the context designated $\mathrm{S}_{\mathbf{2}}+$ during second-order conditioning. An inflation group $X$ testing context analysis, in which context was treated as a repeated measure, indicated a significant main effect for group $[F(2,15)=5.13, p<.02]$, but no effect for context $[F(1,15)<1]$. Subsequent planned comparisons conducted with $\alpha=.05$ revealed that the extinction group differed from both the inflation and the reminder groups, while the latter two did not differ from each other. This

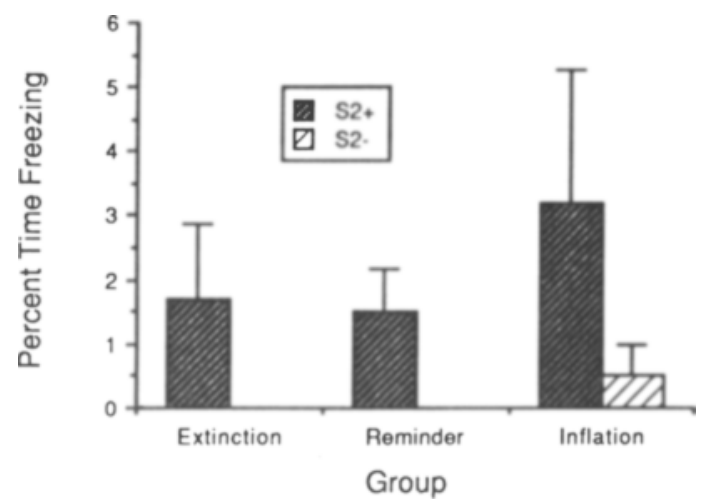

Figure 6. The effects of signaled inflation training on the amount of freezing observed in $S_{\mathbf{2}}$. This postacquisition manipulation failed to significantly affect higher-order responding. 


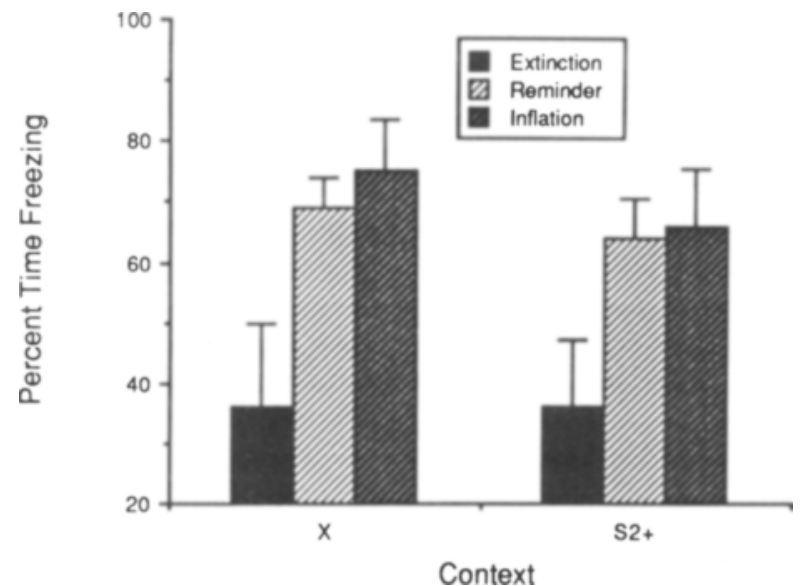

Figure 7. The response to the tone $S_{1}$ used in Experiment 2 as a function of postacquisition treatment and the context in which the stimulus was presented. All $S_{1}-U S$ pairings, during initial acquisition and signaled inflation, occurred in Context $X$. Only nonreinforced presentations of $S_{1}$ were made in $S_{2}+$.

relationship was preserved regardless of the context in which the stimulus was presented.

\section{GENERAL DISCUSSION}

The present experiments demonstrate that rats can form higher-order context-CS associations based on an aversive US. The evidence would indicate that acquisition was dependent on the relation of first-order stimuli to shock as well as the relation of $S_{2}$ to $S_{1}$. Therefore, we would argue for an interpretation solely in terms of higher-order associative learning rather than generalized context fear or similar alternatives. The animals seemed to acquire the higher-order discrimination equally well, whether an explicitly unpaired-and thus possibly inhibitory $-S_{1}$ was presented in $S_{2}$ - or not. The lack of freezing observed during the $4 \mathrm{~min}$ prior to the first presentation of $S_{1}$ indicates that generalized fear from the $S_{1}$ training context was minimal.

The amount of freezing observed in $\mathrm{S}_{2}+$ was greater in Experiment 1 than in Experiment 2. Although the present study was not designed to provide direct comparisons, the strength of second-order responding appeared to be related to the intensity of the shock used during firstorder conditioning, and presumably to the "associative value" of $S_{1}+$. Weaker shock resulted in a smaller secondorder CR. In general, the magnitude of the CR evoked by $S_{2}$ was much less than that of the $S_{1}$ used to support conditioning. Animals in Experiment 2, for example, spent only $3 \%-4 \%$ of their time freezing at asymptote compared to the $60 \%-70 \%$ spent during the tone in the same session. While a larger $C R$ to $S_{2}$ was observed in Experiment 1, the difference between first- and secondorder responding was still substantial. These comparisons may in some sense be flawed in that the time periods of exposure to contextual as opposed to discrete stimuliand thus the "degrees of freedom" or granularity in our time-sampling procedure-are very different. However, we feel that some quantitative statements may be made here, since freezing is a sensitive and reliable assay of conditioned fear that correlates well with more popular measures (Bouton \& Bolles, 1980), and it is readily evoked by both discrete and contextual predictors of shock (Sigmundi \& Bolles, 1983). This point must be emphasized, because in many other preparations the topography of the CR is at least in part determined by the nature of the CS (Holland, 1977; Sigmundi \& Bolles, 1983), and contexts and discrete stimuli often evoke very different conditioned responses that may or may not be directly compared (e.g., see Rescorla, 1984).

It should be noted that at least one potential problem exists in measuring freezing as an index of conditioning when levels of performance are very low, as is the case with second-order responding in this preparation. Interobserver reliability with this technique is very high (normally $96 \%-99 \%$ in our laboratory), but the small amount of error in scoring may be significant when compared with values of less than $10 \%$. Although these results should thus be regarded with some degree of caution, we feel that a number of points argue for their reliability. First, higher-order responding obeyed a characteristic acquisition function: sampling error should behave as a constant and thus have an equivalent affect on scores throughout training. Second, although the difference in performance of freezing in $S_{2}+$ relative to $S_{2}-$ was small relative to that seen in comparable first-order preparations, the animals in $S_{2}$ - consistently made freezing scores very close to zero. And finally, the demonstration of secondorder conditional analgesia in Experiment 1 provides an independent index of conditioning on a baseline similar to that of first-order performance. Thus, while the effect size as measured by freezing was small, we would argue that it is reliable.

As reported by others (Ayres, Axelrod, Mercker, Muchnik, \& Vigorito, 1985; Sigmundi \& Bolles, 1983; Sigmundi, Bouton, \& Bolles, 1980), more freezing was provoked by the first-order tone than by the light. Whereas the modality of $S_{1}$ affected first-order responding, the tone and the light were equally able to support responding to $S_{2}$, as has previously been found with appetitive secondorder conditioning (Holland, 1977). This finding is consistent with a topographical rather than an associative account of the differential ability of the first-order stimuli to evoke freezing. In other words, different amounts of responding to the light as opposed to the tone are not a product of differential "conditionability" or salience. Rather, the two stimuli acquired comparable amounts of associative strength over the course of conditioning, and differences in responding were a product of the given signal's tendency to evoke behaviors incompatible with freezing. Orienting or rearing evoked by the light would be one possible example. This conclusion about CS modal- 
ity differences in the ability to provoke freezing is consistent with others (Ayres et al., 1985; Sigmundi \& Bolles, 1983).

The signaled inflation procedure was designed to be sensitive to a number of possible $\mathbf{S}-\mathrm{S}$ associations in secondorder conditioning, following the logic of Rescorla (1973, 1980). At the same time, this arrangement of stimuli should minimize the amount of generalized context fear that could be produced by unsignaled US presentations in Context X. Since the majority of studies of the rat in aversive preparations have provided evidence for $S-R$ associations in second-order conditioning, we chose a procedure which would be very powerful in detecting S-S learning while not discriminating between different $S-S$ possibilities. Our procedure confounds the possible roles of $S_{2}-S_{1}$ and $S_{1}$-US associations as well as the current values of $S_{1}$ and the US, but provides a sensitive general test, since the critical involvement of any or all of these should manifest itself in the response to $S_{2}$.

If second-order responding were dependent on an S-S association, some effect of our postconditioning manipulation should have been detected. This was not the case. No selective effect on freezing or conditional analgesia was seen in Experiment 1. This null result is inconclusive, however, since a separate independent assessment of the value of $S_{1}$ was not built into the design. But it may be reasonable to assume, on the basis of the trend toward extinction of $S_{1}$ after repeated nonreinforced presentations during second-order acquisition (Figure 3), that reliable extinction occurred by the test day in the animals given additional nonshocked presentations of $S_{1}$ during postacquisition training. Experiment 2 provides this verification, at least with regard to extinction, but it still shows no effect of postacquisition manipulations on second-order responding. The response to $S_{1}$ in the inflation group in this experiment was not significantly higher than that of the reminder group. This may be due to a "ceiling effect" resulting from the use of short-duration punctate CSs. There was ample room, however, to observe an inflation effect on higher-order responding.

The present study is the second demonstration of higherorder conditional analgesia, following Ross (1988). Taken together, the present data and those of Ross would indicate that second-order conditioning as expressed through this response system may be quite a robust phenomenon, since very different conditioning procedures and methods of measuring pain sensitivity were used in the two studies. It should be noted that while extinction of $S_{1}$ had no effect in the present experiments, when Ross devalued shock (the US) by repeated morphine-shock pairings in the test situation, he observed a decreased analgesic conditioned response to $S_{2}$. This finding is inconsistent with the present report insofar as our postconditioning manipulations were ineffective. Further work will be required to determine whether this inconsistency is due to general procedural differences or whether nonassociative devaluation differs from signaled inflation in its ability to modify US memory.
We have presented evidence for a particular type of context-CS association, although at least one other type of learning may occur in this procedure. Recent evidence has argued for a unique role of contextual stimuli in that they may often be associated with a CS-US relation rather than a particular CS or US itself (Bouton \& Bolles, 1985). Since $S_{1}$ was repeatedly presented in both the first-order training context and $\mathbf{S}_{\mathbf{2}}+$, whereas shock was only given in Context $\mathrm{X}, \mathrm{S}_{2}+$ may have acquired, in addition to second-order excitatory strength, the ability to modulate the $S_{1}$-US association. In other words, the rats could have learned that the positive tone-shock relationship was not in effect in $\mathbf{S}_{\mathbf{2}}$ and then responded accordingly. But our data fail to support this particular role for context in these procedures. Figure 7 compares the response to $S_{1}$ in Context $X$, where the tone was reinforced, to the $S_{2}+$ context where shock never occurred. As can be seen, the animals' response to $S_{1}$ was essentially the same in each context.

While these data are not in themselves conclusive with regard to the nature of associations in higher-order context conditioning, we would argue that this preparation produces a form of learning similar to that seen in suppression conditioned with either dissimilar stimuli such as lights and tones, or sequential rather than simultaneous stimulus presentation, even though $S_{\mathbf{2}}$ may be said to completely overlap with $S_{1}$. It is interesting that this procedure may be able to produce both $S-S$ and $S-R$ forms of learning through manipulation of the ratio of $S_{2} / S_{1}$ presentation, thus approximating simultaneous or sequential presentation along a temporal continuum.

\section{REFERENCES}

Amiro, T. W., Bitterman, M. E. (1980). Second-order appetitive conditioning in goldfish. Joumal of Experimental Psychology: Animal Behavior Processes, 6, 41-48.

ARCHER, T., \& Sü̈DÉN, P. O. (1982). Higher-order conditioning and sensory preconditioning of a taste aversion with an exteroceptive $\mathrm{CS}_{\mathbf{1}}$. Quarterly Journal of Experimental Psychology, 34b, 1-17.

Ayres, J. J. B., Axelrod, H., Mercker, E., Muchnik, F., \& VIGorito, M. (1985). Concurrent observations of barpress suppression and freezing: Effects of CS modality and on-line vs. off-line training upon posttrial behavior. Animal Learning \& Behavior, 13, 44-50.

Balsam, P. D., \& Tomie, A. (Eds.). (1985). Context and leaming. Hillsdale, NJ: Erlbaum.

Bouton, M. E., \& Bolles, R. C. (1980). Conditioned fear assessed by freezing and by the suppression of three different baselines. Animal Learning \& Behavior, 8, 429-434.

Bouton, M. E., Bolles, R. C. (1985). Contexts, event-memories, and extinction. In P. D. Balsam \& A. Tomie (Eds.), Context and learning (pp. 133-166). Hillsdale, NJ: Erlbaum.

DAveY, G. C. L., \& McKenNA, I. (1983). The effects of postconditioning revaluation of $\mathrm{CS}_{1}$ and the UCS following Pavlovian secondorder electrodermal conditioning in humans. Quarterly Joumal of Experimental Psychology, 35b, 125-133.

Dubuisson, D., \& DenNis, S. G. (1977). The formalin test: A quantitative study of the analgesic effects of morphine, meperidine, and brain stimulation in rats and cats. Pain, 4, 161-174.

Holland, P. C. (1977). Conditioned stimulus as a determinant of the form of the Pavlovian conditioned response. Journal of Experimental Psychology: Animal Behavior Processes, 3, 77-104. 
Holland, P. C., \& Rescorla, R. A. (1975). Second-order conditioning with food unconditioned stimulus. Journal of Comparative \& Physiological Psychology, 88, 459-467.

Holland, P. C., \& Straub, J. J. (1979). Differential effects of two ways of devaluing the unconditioned stimulus after Pavlovian conditioning. Journal of Experimental Psychology, 5, 65-78.

Marlin, N. A. (1983). Second-order conditioning using a contextual stimulus as $\mathrm{S}_{1}$. Animal Learning \& Behavior, 11, 290-294.

Miller, R. R., Schachtman, T. R. (1985). The several roles of context at the time of retrieval. In P. D. Balsam \& A. Tomie (Eds.), Context and learning (pp. 167-194). Hillsdale, NJ: Erlbaum.

NaIRNe, J. S., Rescorla, R. A. (1981). Second-order conditioning with diffuse auditory reinforcers in the pigeon. Learning \& Motivation, 12, 65-91.

ODLING-SMEE, F. J. (1978). The overshadowing of background stimuli by an informative CS in aversive Pavlovian conditioning with rats. Animal Learning \& Behavior, 6, 43-51.

Pavlov, I. P. (1960). Conditioned reflexes (G. V. Anrep, Trans. \& Ed.). New York: Dover. (Original work published 1927)

RashotTe, M. E. (1981). Second-order autoshaping: Contributions to the research and theory of Pavlovian reinforcement by conditioned stimuli. In C. M. Locurto, H. S. Terrace, \& J. Gibbon (Eds.), Autoshaping and conditioning theory (pp. 139-180). New York: Academic Press.

Rashotte, M. E., Griffen, R. W., \& Sisk, C. L. (1977). Secondorder conditioning of the pigeon's keypeck. Animal Learning \& Behavior, 5, 25-38.

Rescorla, R. A. (1973). Second-order conditioning: Implications for theories of learning. In F. J. McGuigan \& D. Lumsden (Eds.), Contemporary approaches to learning and conditioning (pp. 127-150). New York: Holt, Rinehart \& Winston.

Rescorla, R. A. (1974). Effect of inflation of the unconditioned stimulus value following conditioning. Journal of Comparative \& Physiological Psychology, 86, 101-106.
Rescorla, R. A. (1979). Aspects of the reinforcer learned in secondorder Pavlovian conditioning. Journal of Experimental Psychology: Animal Behavior Processes, 5, 79-95.

Rescorla, R. A. (1980). Pavlovian second-order conditioning. Hillsdale, NJ: Erlbaum.

Rescorla, R. A. (1982). Simultaneous second-order conditioning produces S-S learning in conditioned suppression. Journal of Experimental Psychology: Animal Behavior Processes, 8, 23-32.

Rescorla, R. A. (1984). Association between Pavlovian CSs and context. Journal of Experimental Psychology: Animal Behavior Processes, 10, 195-204.

Rizely, R. C., \& Rescorla, R. A. (1972). Associations in secondorder conditioning and sensory preconditioning. Journal of Comparative \& Physiological Psychology, 81, 1-11.

Robertson, D., Krane, R. V., \& Garrud, P. (1984). Second-order conditioned taste aversion in rats: Shared modality is not sufficient to promote an association between $S_{2}$ and $S_{1}$. Animal Learning \& Behavior, 12, 316-322.

Ross, R. T. (1988). Pavlovian second-order conditioned analgesia. Journal of Experimental Psychology: Animal Behavior Processes, 12, 32-39.

RozeвоOM, W. W. (1958). "What is learned?"'-An empirical enigma. Psychological Bulletin, 65, 22-33.

Sigmundi, R. A., \& Bolles, R. C. (1983). CS modality, context conditioning, and conditioned freezing. Animal Learning \& Behavior, 11, 205-212.

Sigmundi, R. A., Bouton, M. E., \& Bolles, R. C. (1980). Conditioned freezing in the rat as a function of shock intensity and CS modality. Bulletin of the Psychonomic Society, 15, 254-256.

(Manuscript received June 28, 1988; revision accepted for publication December 15, 1988.) 